ISSN 1518-3483

Licenciado sob uma Licença Creative Commons

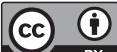

\title{
Educação especial em Roraima: impacto dos processos migratórios na constituição da área
}

La educación especial en Roraima: impacto de los procesos de migración en la formación de la área

Special education in Roraima: Impact of migratory processes on the constitution of the area

\section{Maria Edith Romano Siems Marcondes*}

Universidade Federal de Roraima (UFRR), Boa Vista, RR, Brasil

\section{Resumo}

Neste artigo apresentamos nossa compreensão de como os processos migratórios ocorridos no Território Federal de Roraima entre as décadas de 1970 e 1990 impactaram na constituição dos serviços especializados em educação especial daquele território. Este, é parte de pesquisa que teve como objetivo geral compreender os processos históricos de constituição da educação especial em Roraima oferecidos, em sua totalidade, como parte das atividades desenvolvidas pelo órgão gestor da educação. O processo de pesquisa foi desenvolvido na perspectiva de E. P. Thompson de uma "história vista de baixo";

MERSM: Doutora em Educação Especial, e-mail: edith.romano@ufrr.br 
teve como participantes professores e técnicos atuantes naqueles serviços à época de sua implantação, com os quais foram realizadas entrevistas e mapeados documentos do cotidiano laboral. Foi possível constatar que a chegada de profissionais especializados em áreas como a fonoaudiologia, fisioterapia, educação física e psicologia, oriundos de estados do sul e do nordeste do Brasil, impactaram diretamente nos processos de estruturação dos serviços sendo, inclusive, em alguns casos, esses processos migratórios induzidos pelos próprios gestores, no intuito de captar profissionais especializados aptos a atender demandas da área. Os resultados possibilitam ainda, refletir sobre como a entrada de profissionais migrantes de outras regiões, em que a educação especial se constituía como atividade terapêutica e assistencial, altera os processos de trabalho realizados, levando práticas que em seu nascedouro priorizavam a escolarização dos estudantes com deficiência, sejam transformadas em práticas com foco clínico e terapêutico, acompanhando a tendência das instituições filantrópicas atuantes nos demais estados brasileiros.

Palavras-chave: História da Educação Especial. Educação Especial em Roraima. Migração.

\section{Resumem}

En este artículo presentamos nuestra comprensión de cómo los procesos migratorios que se producen en el Territorio Federal de Roraima entre los años 1970 y 1990 afectaron a la constitución de servicios especializados en educación especial de aquel territorio. Es parte de la investigación y tuvo como objetivo comprender los procesos históricos de constitución de la educación especial en Roraima ofrecido en su totalidad, como parte de las actividades desarrolladas por el órgano de gobierno de la educación. El proceso de investigación se desarrolló en E. P. Thompson perspectiva de una "historia desde abajo"; se contó con la participación de profesores y técnicos que trabajaban en esos servicios en el momento de su implementación, con los que se llevó a cabo entrevistas y se hizo um estúdio de documentación del diário laboral. Se encontró que la llegada de profesionales especializados en áreas tales como terapia del habla, fisioterapia, educación física y la psicología, procedentes de los estados del sur y en el noreste de Brasil, impactaron directamente en los procesos de estructuración de los servicios e incluso en algunos casos, éstos procesos de migración fueron inducidos por los propios directores, con el fin de atraer a profesionales calificados, capaces de satisfacer las 
demandas de la zona. Los resultados también permiten reflexionar sobre cómo el ingreso de inmigrantes profesionales de otras áreas donde la educación especial, constituida como una actividad terapéutica y de bienestar altera los processos de trabajos realizados, dando lugar a que práticas que, en su lugar de nacimiento daban prioridad a la educación de los estudiantes con discapacidad, se transformen en prácticas con un enfoque clínico y terapéutico, siguiendo la tendencia de las organizaciones benéficas que operan en otros estados de Brasil.

Palabras clave: Historia de la Educación Especial. Educación Especial en Roraima. La migración.

\section{Abstract}

In this article we present our understanding of how the migratory processes that occurred in the Federal Territory of Roraima between the 1970s and 1990s impacted on the constitution of specialized services in special education in that territory. It is part of a research that had as general objective to understand the historical processes of constitution of special education in Roraima offered, in its totality, as part of the activities developed by the managing body of education. The research process was developed from the perspective of E. P. Thompson of a "history seen from below"; Had as participants teachers and technicians active in those services at the time of its implementation, with which interviews and mapped documents of daily work were carried out. It was possible to verify that the arrival of specialized professionals in areas such as phonoaudiology, physiotherapy, physical education and psychology, coming from the states of the south and northeast of Brazil, had a direct impact on the processes of structuring the services, including in some cases, these Migratory processes induced by the managers themselves, in order to attract specialized professionals able to meet the demands of the area. The results also allow us to reflect on how the entry of migrant professionals from other regions where special education was constituted as a therapeutic and care activity alters the work processes carried out, leading to practices that prioritized the schooling of students with disabilities, Are transformed into practices with a clinical and therapeutic focus, following the trend of philanthropic institutions that are active in other brazilian states.

Keywords: History of Special Education. Special Education in Roraima. Migration. 


\section{Introdução}

Os serviços especializados em educação especial em Roraima, por serem desde sua implantação integralmente vinculados a setores governamentais responsáveis pela gestão da educação, têm uma característica que os faz peculiares em relação aos demais estados brasileiros. Isto contraria o sentido comum seguido em outras localidades, que tem a maior parte das ações de educação especial vinculados a instituições de natureza privada e filantrópica, cujo foco central é de cunho assistencial e/ou terapêutico, embora sejam beneficiados também com recursos públicos que seriam destinados ao financiamento da educação.

Conforme aponta Siems (2016), em Roraima, a implantação dos serviços especializados em educação especial deu-se entre meados dos anos 1970 e 1985, período de atuação do governo militar ditatorial. Este governo, adotando estratégias próprias da perspectiva militar em gestão, assumiu, como foco prioritário de ação, a atenção aos territórios federais, na perspectiva do "integrar para não entregar" que se desenvolveu em toda a região amazônica.

As ações realizadas no campo da educação, especial em Roraima, se caracterizam por serem a aplicação integral das etapas e propostas do governo central na reforma educacional trazida pela lei 5692/71 (BRASIL, 1971), atendendo às orientações projetadas pelo Centro Nacional de Educação Especial - CENESP, órgão coordenador da educação especial, criado em 1973 com a missão de operacionalizar o definido no artigo $9^{\circ}$ daquela lei :

Os alunos que apresentem deficiências físicas ou mentais, os que se encontrem em atraso considerável quanto à idade regular de matrícula e os superdotados deverão receber tratamento especial de acordo com as normas fixadas pelos competentes Conselhos de Educação.

Esta fidelidade na implantação de propostas, especificamente como preconizado nos documentos norteadores do CENESP, e favorecido 
pela inexistência de organizações da sociedade civil organizadas ou outros serviços privados, filantrópicos ou assistenciais implantados que pudessem interpor movimentos de resistência ou de confrontação com as práticas propostas. Nesse sentido, observa-se uma implantação integral de modelos, ao contrário do vivenciado no restante do país em que movimentos sociais e representações da sociedade civil apresentaram resistências à implantação das políticas de iniciativa governamental em função de interesses que, por vezes, se sobrepunham ao já instituído.

As propostas do CENESP para a educação especial trazem as marcas das consultorias recebidas de técnicos de origem norte-americana (RAFANTE, 2015). Estes, em muitos casos, apresentavam modelos que demandavam a formação específica de recursos humanos e que também se apoiavam na atuação de profissionais de diversas áreas clínicas, dentro do modelo médico e terapêutico que orientava os serviços especializados da época.

Roraima, território federal que teve sua ocupação efetivada tardiamente, em consequência de suas condições geográficas peculiares, ao se ver confrontada com as demandas trazidas pela implantação de serviços especializados em educação especial, passa a também requerer a atuação de profissionais com alta qualificação, em um momento em que não existem instituições de ensino superior aptas a formar os profissionais necessários ao desenvolvimento dos serviços ou disponíveis para inserção nos espaços de trabalho.

É neste contexto que se observa a abertura de um movimento migratório expressivo, com a contratação, em outros estados brasileiros, dos profissionais que o Território demandava para a efetivação dos projetos de interesse do governo central, dentre eles, a educação especial.

Estes profissionais, capacitados em outros estados brasileiros e com experiências em serviços e instituições de educação especial de enfoque clínico-terapêutico ou assistencial, trazem aos serviços aqui em desenvolvimento, suas práticas, impactando na trajetória de sua implementação. 
Dentre estes atores, optamos por trazer ao nosso trabalho a voz de professores, personagens habitualmente silenciados nos registros históricos da educação especial e, que normalmente focam sua atenção ou nos documentos oficiais da área ou de pensadores/técnicos os quais tiveram atuação destacada, com perfil que influenciou diretamente as políticas públicas.

Nosso foco, coerente com a perspectiva de E. P. Thompson de compreensão dos processos históricos, era analisar como os docentes que efetivamente trabalharam nos serviços, experienciaram os impactos da presença de profissionais que para cá migram, trazendo aos serviços as concepções construídas em contextos diferenciados.

Entendemos, como Thompson (1981, p. 58) que "qualquer momento histórico é ao mesmo tempo resultado de processos anteriores e um índice da direção de seu fluxo futuro". Neste sentido, construímos este trabalho apresentando, em um primeiro momento, referências sobre o contexto social e econômico de Roraima e suas relações com o processo migratório, no período de 1970 e 1990. Em sequência, discutimos o processo de incorporação de alguns técnicos que migram para Roraima com a finalidade de integrarem-se aos serviços e, a partir destes dados, nossa análise do impacto da atuação desses migrantes no cotidiano dos docentes pioneiros da educação especial.

\section{Metodologia}

A pesquisa que dá origem a este artigo teve por objetivos compreender o processo histórico de constituição dos serviços especializados de educação especial em Roraima. Estes são integralmente oferecidos como serviços públicos, de responsabilidade governamental e gerenciados, em sua ampla maioria pelo órgão gestor da educação, diferenciando-se da condição geral do país em que predomina, na educação especial, o protagonismo de instituições privadas e filantrópicas. 
Assumimos como perspectiva metodológica os fundamentos do historiador Edward Palmer Thompson, considerando que o destaque posto em sua produção como historiador é o de defender uma "história vista de baixo", que busque compreender os processos históricos não a partir de um pensamento único constituído pela instância de poder de cada período, mas como a história de homens e mulheres reais, por vezes anônimos. Para ele, são estes seres que, com suas experiências, resistências e ações práticas, em muitos casos aparentemente passivas, constroem um fluxo histórico que não é marcado por uma evolução, mas entremeado por avanços, retrocessos, conflitos e contradições (THOMPSON, 1981).

Neste sentido, valoriza-se significativamente as experiências como vivenciadas pelos sujeitos, em nosso caso, os atores que protagonizaram a construção dos serviços especializados de educação especial no atual estado de Roraima.

Em termos de procedimentos metodológicos, realizamos entrevistas com um grupo de 08 professoras e técnicas que atuaram na implantação dos serviços especializados e analisamos documentos do cotidiano laboral dessas equipes como livros de atas, fotos, relatórios e correspondências profissionais que nos permitiram ter um painel do trabalho eminentemente educativo que se desenvolvia com os estudantes com deficiência, nesta etapa inicial.

No conjunto das entrevistas, identificamos o papel relevante dos processos migratórios na estruturação das unidades especializadas em educação especial, razão pela qual direcionamo-nos ao estudo de referenciais bibliográficos que nos possibilitassem ampliar a compreensão do fenômeno migratório no contexto da região onde se situa nosso estudo.

\section{Migração em Roraima}

A região que constitui o extremo norte do Brasil é cercada de mitos, como o da existência de um Eldorado, que motivou a realização de expedições europeias na região desde o século XVIII. 
Movimentos migratórios para a região, como a adoção de políticas que induzissem a ocupação do espaço, foram registradas desde o período do Brasil Colônia, passando pelo Império. Porém, as condições climáticas, as dificuldades de acesso e a natureza indomável, representaram forte limitador à fixação de colonos e migrantes até o final do século XIX.

No século XX, autores que analisam os movimentos de expansão populacional como Santos (2004) destacam que "uma imagem de imobilidade social transparece nos diversos estudos que abrangem períodos anteriores a 1943" quando se estabelece o Território Federal do Rio Branco, posteriormente renomeado como Território Federal de Roraima.

Barros (1995) e Santos (2004), apontam que, a partir dos anos 1940, a população de migrantes amplia-se significativamente, atraída pela mineração e pelas atividades administrativas de uma região cuja expansão passa a ser fomentada e apoiada pelo governo federal.

A implementação de políticas governamentais de incentivo à ocupação territorial, embora nem sempre em trajetória contínua, tem um marco importante no período do Estado Novo com a criação dos Territórios Federais. Sua consolidação e aceleração se dá principalmente no conjunto de projetos de desenvolvimento econômico das fronteiras e da própria região amazônica, que acompanharam o processo de militarização trazido pelo regime militar pós 1964. São ações que almejam a construção de uma identidade nacional a partir de projetos de expansão econômica centralizados na ocupação produtiva da terra.

Esta abertura para a ocupação pautada na cessão de pequenas propriedades para uso em perspectiva agropecuária, marca as ações oficiais de incentivo à migração, levando à intensificação desses processos migratórios. Também, conta com ações do governo central no esforço de construção de estratégias à superação das limitações impostas pelas peculiaridades geográficas que dificultaram o acesso à área anteriormente.

Ao longo das décadas de 1960 e 1970, há um forte aporte de recursos do governo central destinado à implantação de uma infraestrutura de acesso e serviços. Esta se expande com a implantação dos batalhões militares, que assumem diretamente a responsabilidade pela construção 
de pontes e estradas de acesso. Esta abertura de acessos é consorciada à implantação de projetos de colonização agrária com a expansão de minifúndios e sua consequente demanda pela implantação de serviços básicos de educação, saúde e segurança, conforme indicado por Freitas (1991, p. 78):

Nos Territórios a ocupação foi feita por minifúndios (de maior poder modificador da taxa de incremento populacional). Os minifúndios, por trabalharem com a mão-de-obra familiar exigem do Estado maiores investimentos em áreas de Saúde, Educação e Segurança Pública.

Santos (2000, p. 11), referindo-se aos esforços de povoamento da região amazônica, destaca que, no século XX, "a região foi objeto da política que se propunha equacionar o problema dos homens sem terras do Nordeste, com as terras sem homens da Amazônia". Outros estudos que tomam os fluxos migratórios em Roraima como foco central e os impactos econômicos, sociais e culturais da chegada dos migrantes são os de Santos (2010), Souza (2004) e Magalhães (2006).

É Souza (2004) que nos apresenta um painel dos dados censitários gerais da segunda metade do século $\mathrm{XX}$ :

Tabela 1 - População residente para o Brasil, Região Norte e Roraima - 1950/2000

\begin{tabular}{lrrrrrr} 
& \multicolumn{1}{c}{1950} & \multicolumn{1}{c}{1960} & \multicolumn{1}{c}{1970} & \multicolumn{1}{c}{1980} & \multicolumn{1}{c}{1991} & \multicolumn{1}{c}{2000} \\
\hline Brasil & $\mathbf{5 . 1 9 4 1 . 7 6 7}$ & $\mathbf{7 0 . 0 7 0 . 4 5 7}$ & $\mathbf{9 3 . 1 3 9 . 0 3 7}$ & $\mathbf{1 1 9 . 0 0 2 . 7 0 6}$ & 146.825 .475 & 169.799 .170 \\
\hline Região Norte & 1.834 .185 & 2.561 .782 & 3.603 .860 & 5.880 .268 & 10.030 .556 & 12.900 .704 \\
Roraima & 17.834 & 28.304 & 40.885 & 79.159 & 217.583 & 324.397 \\
\hline
\end{tabular}

Fonte: IBGE - Censos Demográficos de 1950/2000

Observando-se o crescimento populacional ao longo de 50 anos, vemos que, em termos nacionais, registra-se um aumento em números absolutos que se aproxima de três vezes e meia; na região norte, aproximadamente sete vezes e, em Roraima, esse crescimento em 50 anos, é de dezoito vezes, com um forte impulso entre os anos 1970/1980. 
Analisando-se estes dados em termos de taxas geométricas temos os seguintes percentuais de crescimento populacional:

Tabela 2 - Taxa média geométrica de crescimento populacional para o Brasil, Região Norte e Roraima

\begin{tabular}{lrrrrr} 
& $\mathbf{1 9 4 0 / 1 9 5 0}$ & \multicolumn{1}{c}{$\mathbf{1 9 5 0 / 1 9 6 0}$} & $\mathbf{1 9 6 0 / 1 9 7 0}$ & $\mathbf{1 9 7 0 / 1 9 8 0}$ & \multicolumn{1}{c}{$\mathbf{1 9 8 0 / 1 9 9 1}$} \\
\hline Brasil & $\mathbf{2 , 3 9}$ & $\mathbf{2 , 9 9}$ & $\mathbf{2 , 8 9}$ & $\mathbf{2 , 4 8}$ & $\mathbf{1 , 9 3}$ \\
\hline Região Norte & 2,29 & 3,34 & 3,47 & 5,02 & 3,85 \\
Roraima & 5,49 & 4,65 & 3,75 & 6,83 & 9,63 \\
\hline
\end{tabular}

Fonte: IBGE, Censos Demográficos de 1950/1991.

Esse crescimento expressivo de Roraima, é impulsionado prioritariamente pelo interesse na atividade mineradora, mas também pela possibilidade de ocupação de terras da União que pudessem vir a constituir-se em propriedades particulares. Em seu estudo, Souza (2004) destaca a predominância, no final dos anos 1990, de entrada via terrestre de migrantes, um indicativo da precariedade de condição socioeconômica desses, se consideradas as dificuldades ainda existentes de acesso por esta via, que só contará com estradas asfaltadas e pontes no início do século XXI.

A análise de informações estatísticas (RORAIMA, 1981) indicava, por exemplo, que, no período de outubro a dezembro de 1980, dos 2170 migrantes que ingressaram no território, 1156 eram garimpeiros, 346 agricultores, 323 envolvidos em atividades de outra natureza e 345 eram dependentes.

Santos (2010), entendendo a migração como uma estratégia de resistência dos trabalhadores frente a processos de expropriação da terra sofridos pelos migrantes em seus estados de origem, estuda os processos dos assentamentos de Jauaperi e Jatapu e o surgimento das vilas e aglomerados ao longo da Perimetral Norte. Analisa a migração e organização dos trabalhadores que se deslocaram entre os anos de 1970 e 1990 no sudeste de Roraima.

Reiterando essa perspectiva de ser a migração uma estratégia de resistência dos trabalhadores, Siems (2013) indica que: 
$\mathrm{Na}$ apresentação de um Termo de Referência realizado em meados de 1985 no âmbito da Secretaria de Planejamento e Coordenação do Governo de Roraima que relata um trabalho denominado como "Metodologia da Aprendizagem da Participação e Organização das Comunidades", há um volume expressivo de depoimentos de trabalhadores rurais e em como estes viviam suas relações com Roraima e como vivenciavam os processos de educação. Em um dos depoimentos vemos uma manifestação que referenda essa perspectiva: "70\% do povo que vem nesses projetos de assentamento, são expulsos por latifundiários em outras regiões ou expulsos das periferias das grandes cidades. Uma outra parte, vem explorar este povo" (p. 90-91, grifo do autor).

Esses processos intencionais de incentivo à ocupação territorial, são acompanhados também da implantação de uma estrutura de serviços públicos que demandava a atuação de profissionais especializados, em condições de assumirem, nos órgãos públicos, atividades de maior especificidade. Era a demanda por profissionais com formação em nível superior, em um estado que até 1989, não iria dispor de nenhuma instituição de ensino superior e, que já não poderia ser suprida apenas pelos cidadãos locais que se deslocassem para formação em outras localidades e depois retornassem à sua terra de origem.

É relevante considerar ainda que, no período compreendido entre 1943 e 1990, sendo Território Federal, Roraima vivenciava, política e economicamente, uma centralização administrativa, sendo seu governador designado diretamente pela Presidência da República, inexistindo poderes legislativo ou judiciário locais. Estes governadores normalmente se faziam acompanhar de equipes que não tinham, necessariamente, vínculos com a região. O governador era responsável, inclusive, pela designação do prefeito da capital.

No caso de Roraima, esses governadores sofreram, entre as décadas de 1940 e 1960, uma forte rotatividade, estimada por Freitas (1993, p. 160), em uma permanência média de 15,8 meses cada. No período pós 1964, eles passam a ser representantes de alta patente da aeronáutica que aqui permanecem por períodos mais longos, dispondo de 
maior estabilidade no aporte de recursos fazendo de seus espaços de atuação campos de implantação dos projetos de interesse do governo central.

Dentre os projetos de interesse do governo federal, destacamos a reforma educacional que traz entre seus desafios a inclusão da educação especial como política pública de responsabilidade governamental e, que sofre em sua estruturação forte influência dos migrantes integrados à sua força de trabalho.

\section{Educação Especial em Roraima: impacto dos processos migratórios na constituição da área}

O processo de constituição da Educação Especial em Roraima guarda características específicas em relação ao restante do país. Enquanto na maioria dos estados brasileiros, diante da ausência do Estado na condução de atividades educacionais para pessoas com deficiência vemos, desde 1926, ano em que se instala o primeiro Instituto Pestallozzi, no Rio Grande do Sul, o nascimento e expansão de organizações de natureza filantrópica como as Associações de Pais e Amigos dos Excepcionais (APAE) e Institutos como o Pestalozzi.

Em Roraima, a criação de serviços especializados em educação especial ocorre em 1975 como iniciativa governamental no âmbito da Divisão de Educação e Saúde que, posteriormente, se tornará a Secretaria de Educação e Cultura (SEC).

É no órgão gestor da educação do território, com a participação ativa de professores, que se implantam os vários serviços especializados, os quais virão a ser oferecidos à comunidade local dentre os quais destacamos: a Escola de Audiocomunicação, os Centros Especializados de Educação Especial de Boa Vista e Caracaraí, a Sala de Recursos para Deficientes Visuais, equipes de apoio à escolarização de alunos nas várias classes especiais que se instalam em diferentes escolas e também equipes as quais apoiam os profissionais do ensino regular que tivessem estudantes com deficiência matriculados em classes comuns, já em número expressivo ao longo dos anos 1990. 
Mas, como se dá a implantação de novos setores e serviços tão especializados, em uma localidade onde não existiam, a priori, profissionais capacitados ou uma instituição formadora de ensino superior que oferecesse respostas a estas demandas? Já no processo inicial de pesquisa identificamos que, a primeira implantação de serviços ocorre diretamente através da contratação de uma professora que havia recentemente migrado do nordeste para Roraima. No depoimento da primeira professora selecionada para o atendimento a estudantes com deficiência, a professora Clotilde Parima Rodrigues enuncia:

Eu sou cearense. Eu trabalhava na cidade do Crato já com Educação Especial. Formada professora naquela época no Normal Pedagógico. Fazia faculdade de Letras quando comecei a trabalhar com Educação Especial na cidade do Crato. Fiz cursos em Fortaleza, fiz estágios no Instituto Pestalozzi. E treinamentos na própria cidade do Crato, foi quando em 1973, por um acaso eu mudei-me aqui pra Roraima. Cheguei naquela época aqui, não tinha faculdade. Deixei o meu currículo na secretaria de Educação. Quando foi na época do governador, Ramos Pereira em 1975 pensaram em criar Educação Especial no Território, e começaram a ver os currículos no setor de pessoal da secretaria e então encontraram o meu, e que eu já havia trabalhado com Educação Especial no Estado do Ceará, e me chamaram pra perguntar como era aquele procedimento, e se eu topava fazer parte da educação especial como professora. Eu disse que sim. Que gostava muito daquele tipo de trabalho que já tinha feito no Ceará. Então aí criaram uma coordenação. E, em 1976 começou a funcionar uma sala de aula, numa sala cedida da escola Monteiro Lobato. Eram seis ou oito pessoas portadoras de necessidades especiais, tudo junto, deficiência auditiva, visual, deficiência física, síndrome de down, tudo numa única sala na escola Monteiro Lobato.

A situação desta professora, que trazia em sua formação cursos e atividades profissionais anteriores em educação especial, é diferenciada em relação ao conjunto das docentes que viriam a compor as equipes de atuação na área. O grupo que posteriormente se constituiu era composto em sua quase totalidade por docentes com formação apenas em magistério de nível médio, que foram posteriormente capacitadas em serviço, em cursos oferecidos pelo CENESP em todo o país. 
Este perfil docente é percebido nos relatórios e discursos que apresentam as práticas desenvolvidas com os estudantes, muito mais próximas de atividades de escolarização como as oferecidas a todos os estudantes do que de processos clínico-terapêuticos como os desenvolvidos no restante do país, que tem como nascedouro o foco assistencial ou ocupacional, sem maiores vínculos com educação escolar.

A inexistência de faculdade era sentida como fator limitador no desenvolvimento do Território, existindo apenas o curso de Magistério em nível médio. Excepcionalmente, a Universidade Federal de Santa Maria (UFSM) mantinha aqui um campus avançado que chegou a oferecer turmas presenciais de Estudos Sociais, Letras e Pedagogia, em caráter excepcional. Além disso, a UFSM realizava ações dentro do Projeto Rondon, enviando sistematicamente equipes de estudantes para estágios em diferentes cidades e vilas do território.

Nas entrevistas realizadas com as professoras pioneiras da implantação dos serviços de educação especial em Roraima é frequente a referência às atividades desenvolvidas por estes estagiários "rondonistas" com destaque para os estudantes de Fonoaudiologia, Fisioterapia, Educação Física e Psicologia. Como estes eram, em sua maioria, estudantes em fase final de formação, registramos a ocorrência de convites dirigidos pelos gestores a alguns deles para que retornassem ao território quando formados, para assumirem postos de trabalho nos serviços em implantação. No relato da professora Maria Mirna Souto Maior Sarah, professora que por muitos anos coordenou a Divisão de Educação Especial: "até fisioterapeuta a gente conseguiu pelo projeto Rondon. O Alves veio estagiar aqui quando estava terminando o curso e a gente já acertou para que ele retornasse quando terminasse para trabalhar aqui".

Há outros registros de estagiários do Projeto Rondon que retornam à Boa Vista assim que concluída sua formação e se integram às equipes técnicas e gestoras da educação especial. Destacamos o caso da fonoaudióloga gaúcha Rosana Magalhães, cuja carreira inicia-se no Escola/ Centro de Educação Especial do Parque Anauá e que tem protagonismo 
na educação de surdos e na implantação de serviços de avaliação auditiva no Território.

A primeira vez que eu cheguei aqui, estagiária do Projeto Rondon, em junho de 1983, passei um mês aqui, como estagiária, faltando seis meses pra eu me formar. Aí passei um mês aqui estagiando. Trabalhei junto à Escola de Educação Especial, aqui na capital e no interior em Caracaraí também, e trabalhei em escolas do ensino regular, dentro do Projeto Rondon, como fonoaudióloga. Na época não tinha fono aqui. Não tinha fono e tinha uma necessidade imensa. Não tinha nem uma fono e aí na própria secretaria de educação o pessoal disse: 'olha, se você quiser voltar pra cá, você tem emprego garantido'. Aqui não tinha nem uma fono, você vê que a necessidade era muito grande e foi assim que eu acabei voltando.

Outros profissionais, como professores de educação física, fonoaudiólogos, psicólogos, pedagogos e terapeutas ocupacionais também oriundos de outros estados, se agregam aos órgãos gestores da Secretaria de Educação e da Divisão de Educação Especial e, em muitos casos, passam a atuar diretamente com os estudantes, em especial no Centro de Educação Especial, popularmente conhecido como "Escolinha do Parque Anauá”.

Os estudos que aqui realizamos olham o processo do ponto de vista da necessidade de construção de uma educação escolar inclusiva, que considere estudantes com deficiência como estudantes aos quais devem ser oferecidos meios de escolarização com sucesso em que o acesso, para além da matrícula se constitua como acesso ao conhecimento socialmente acumulado. Esta ótica só vai se constituir em âmbito nacional nos primeiros anos do século XXI.

Em nosso caso, é com esse parâmetro, atualmente ainda relativamente utópico, que analisamos o impacto do processo migratório de técnicos especializados, junto à educação especial em Roraima. Entendemos, entretanto, como destaca Thompson (1981, p. 52) que, "cada idade, ou cada praticante, pode fazer novas perguntas à evidência histórica ou pode 
trazer à luz novos níveis de evidência”. Além disso, é este mesmo autor que orienta nosso fazer quando indica que,

Ao reconstruir esse processo, ao mostrar como a causação na realidade se efetuou, devemos, à medida que nossa disciplina o permita, controlar nossos próprios valores. Uma vez, porém, reconstruída essa história, temos liberdade de oferecer nosso julgamento a propósito dela.

Nesse sentido, não podemos nos furtar a apresentar nossa compreensão quanto ao impacto da chegada de especialistas, cuja formação para o atendimento a pessoas com deficiência se deu na lógica assistencial e/ou terapêutica, com saberes do campo clínico ou terapêutico. Em nossa análise, esta lógica se sobrepôs à busca de estratégias de escolarização que as professoras pioneiras vinham construindo quando olhavam os estudantes com deficiência, apenas como estudantes e buscavam, a partir da perspectiva pedagógica, construir caminhos de ensino que levassem à necessária aprendizagem.

\section{Considerações finais}

No processo de pesquisa que realizamos, ao investigar quais eram as práticas dos professores que iniciam os serviços, observamos uma prevalência de relatos que indicam a preocupação com a alfabetização das crianças e uma rotina de atividades pedagógicas próprias às atividades desenvolvidas em turmas de educação pré-escolar, mesmo quando os alunos apresentavam idade mais elevada.

Como destaca a professora Clarice Diniz, referindo-se à como desenvolviam seu trabalho pedagógico: "o que tinha de diferente era o tempo. Porque o que você faz com a criança dita normal, com o 'especial' você consegue, mas você demora. Então o que tinha era o tempo, que era maior. Mas nos dávamos aula, aula mesmo, aula normal". O foco central do trabalho, no relato dos professores, era o desenvolvimento da 
motricidade fina, de noções de lateralidade, bem como os demais conceitos entendidos como preparatórios à alfabetização e exercícios de alfabetização em si.

Com a chegada dos técnicos nos serviços, há uma mudança na conduta dos professores. Entendendo que os especialistas das áreas clínicas teriam domínio de conhecimentos superior em relação às práticas adequadas ao desenvolvimento dos estudantes com deficiência, observa-se duas situações: em um primeiro momento, na análise do relato das professoras pioneiras na implantação da educação especial que foram entrevistados, estes passam a aguardar as ações e orientações de fisioterapeutas, fonoaudiólogos e psicólogos, na expectativa de que estes apresentem quais as alternativas pedagógicas para o desenvolvimento de sua ação docente.

Em um segundo momento, se vê o registro de que os atendimentos terapêuticos dos estudantes passam a ser feitos no próprio Centro de Educação Especial, nos horários que deveriam ser destinados às aulas e as atividades próprias ao ensino, reduzindo significativamente o volume de carga horária em que os estudantes estariam expostos à escolarização.

Identifica-se nos relatos e na observação dos planos de ensino ou cadernos de relatório, uma crescente substituição da atividade pedagógica, que até então era feita por professores capacitados ao exercício da docência, por uma aplicação de atividades terapêuticas em relação às quais os docentes recebiam dos técnicos apenas instruções aligeiradas e pontuais, o que fragilizava sua realização.

Dessa forma, a implantação inicial dos serviços especializados de educação especial focados na escolarização dos estudantes, interligados às escolas e aos demais setores vinculados ao órgão gestor da educação, tendo como protagonistas os professores, vai sendo gradativamente transformada num setor paralelo, com forte protagonismo de psicólogos, fonoaudiólogos e fisioterapeutas exercendo, como é próprio aos profissionais destas áreas, atendimentos terapêuticos corretivos ou compensatórios.

Entendemos que estes atendimentos eram necessários e importantes, entretanto, não entendemos como conveniente o fato de 
tornarem-se substitutivos das atividades acadêmicas, como aconteceu. Esta alteração nas práticas, reflete-se inclusive na própria identidade da principal instituição de educação especial do estado que ao longo das quase três décadas em que existiu, sediada no Parque Anauá, viveu sucessivas alterações de denominação como "Escola de Educação Especial" ou como "Centro de Educação Especial", a depender da correlação de forças entre os técnicos atuantes.

Destaca-se ainda o fato de que os profissionais ingressantes no Território Federal de Roraima, o faziam em sua maioria, por indicação direta. Eram contratações desvinculadas da realização de concurso, muitas vezes realizadas dentro de grupos familiares ou de amizades e que oportunizavam ao profissional tornar-se servidor público federal, com possibilidades de posterior retorno a seus estados de origem, perspectiva que fragilizava ainda mais a construção de vínculos de compromisso com a comunidade local.

Esse processo de redistribuição dos servidores tem um forte impacto no momento de transição do Território a Estado da Federação, conforme definido na Constituição Federal de 1988 para ocorrência em 1990. Na regra definida para esta transição, os servidores já atuantes nos Territórios - em sua maior parte não concursados, seriam enquadrados no quadro de servidores da União e, a partir daí os governos estaduais deveriam realizar concursos específicos para o preenchimento de suas necessidades, contando, entretanto, com a possibilidade de aproveitamento dos servidores da União em suas equipes.

É o momento em que setores precisam reorganizar-se, mas agora já fortemente impactados pelas ações e concepções dos migrantes que por aqui passam e dos novos que por aqui continuarão a chegar nos próximos anos. Como relatou Maria Mirna Souto Maior Sarah referindo-se ao impacto da evasão de profissionais neste momento de transição: "E o que desfalcou foi isso que quando passou a Estado, quem era do território podia pedir redistribuição e ele foi pro Nordeste. Os que eram do nordeste foram". 
Eram os anos 1990, momento em que o país atravessava um momento de instabilidade expressiva. Em 1989 efetiva-se a criação da Universidade Federal de Roraima e, analisando os dados populacionais, é possível identificar uma expansão populacional extremamente significativa. Segundo dados censitários do IBGE, em 1991 a população era de 217.583 habitantes e no ano 2000 chega a 324.397 habitantes, muitos desses atraídos não apenas pela possibilidade de acesso a terras em projetos de assentamento, ou de oportunidades de ingresso na atividade comercial, mas também pela oferta de vagas em concursos públicos nas mais diversas áreas, inclusive na Educação e na Educação Especial, contribuindo para a consolidação da área no setor público tanto em âmbito estadual quanto municipal.

$\mathrm{Na}$ atualidade, o Estado de Roraima, que ainda mantém a concentração de todos os serviços de educação especial sob responsabilidade dos setores públicos, como responsabilidade governamental, ainda tem em suas equipes um volume expressivo de migrantes de todo o país. Entretanto, com o fortalecimento das atividades das universidades públicas (federal e estadual), além do maior acesso a cursos de pós-graduação à distância ou mesmo presenciais em faculdades particulares, já conta com um volume significativo de profissionais qualificados ao desempenho das atividades especializadas em educação especial no próprio estado.

Entendemos, entretanto, como muito relevante o reconhecimento do pioneirismo na oferta de educação especial pelo poder público que este ex-território apresenta e, em nosso entendimento, significa o reconhecimento pioneiro de pessoas com deficiência como sujeitos de direito, antecipando, já nos anos 1970, o que só viria a ser efetivamente estabelecido em âmbito nacional a partir da Constituição Federal de 1988. 


\section{Referências}

BARROS, N. C. de. Roraima: paisagens e tempo na Amazônia Setentrional. Recife: Editora Universitária UFPE, 1995.

BRASIL. Lei n 5692, de 11 de agosto de 1971. Fixa diretrizes e bases para o ensino de $1^{\circ}$ e $2^{\circ}$ graus, e dá outras providências. Diário Oficial da União, Brasília, DF, 12 ago. 1971. Disponível em: <http://www2.camara.leg.br/legin/fed/lei/19701979/lei-5692-11-agosto-1971-357752-publicacaooriginal-1-pl.html〉. Acesso em: 09 jan. 2017.

RAFANTE, H. C. Política de Educação Especial no Brasil: a relação entre o estado, a sociedade civil e as agências internacionais na criação do CENESP. Anais da $37^{a}$ reunião anual da ANPEd, 2015. Disponível em: <http://www.anped.org.br/sites/ default/files/trabalho-gt15-3916.pdf>. Acesso em: 09 jan. 2017.

FREITAS, A. Políticas Públicas e Administrativas de Territórios Federais Brasileiros. 2 ed. Boa Vista: Corprint Gráfica e Editora Ltda, 1991.

MAGALHÃES, M. G. S. D. Amazônia Brasileira: processo histórico do extrativismo vegetal na mesorregião sul de Roraima. Tese (Doutorado em História) - Pontifícia Universidade Católica do Rio Grande do Sul, Porto Alegre, 2006.

RORAIMA. Secretaria de Planejamento. Informações estatísticas. v. 2, n. 1. Boa Vista: Gráfica da SEPLAN, 1981.

RORAIMA. A História Politica e Administrativa de Roraima: de 1943 a 1985. Manaus: Editora Umberto Calderaro Ltda, 1993.

SANTOS, H. E. A. dos. Fatores de crescimento de Roraima. 98 f. Dissertação (Mestrado em Economia) - Universidade Federal do Rio Grande do Sul (UFRGS), Porto Alegre, 2000.

SANTOS, M. J. Em Busca da Terra: migração, organização e resistência na política de colonização no sudeste de Roraima (1970 - 1990). 271 f. Dissertação (Mestrado em História) - Universidade Federal do Amazonas (PPGH/UFAM), Manaus, 2010. 
SANTOS, N. P. D. Políticas Públicas, Economia e Poder: o estado de Roraima entre 1970 e 2000. 271 f. Tese (Doutorado em Desenvolvimento Sustentável do Trópico Úmido) - Núcleo de Altos Estudos Amazônicos, Universidade Federal do Pará (UFPA), Belém, 2004.

SIEMS, M. E. R. Educação Especial em Roraima: história, política e memória. 358 f. Tese (Doutorado em educação especial) - Programa de Pós-graduação em educação especial da UFSCar, Universidade Federal de São Carlos, São Carlos, 2013. SIEMS, M. E. R. Educação Especial em Roraima, 1970 a 2001: efeitos do regime militar. São Carlos: Pedro e João Editores, 2016.

SOUZA, C. M. de. História, Memória e Migração: processos de territorialização e estratégias de inserção entre migrantes gaúchos radicados em Roraima. Tese (Doutorado em História) - Pontifícia Universidade Católica do Rio Grande do Sul, Porto Alegre, 2004.

THOMPSON, E. P. A Miséria da Teoria. Rio de Janeiro: Zahar Editores, 1981.

Recebido: 10/12/2016

Received: 12/10/2016

Aprovado: 15/01/2017

Approved: 01/15/2016 
